\title{
DESIGN E INFÂNCIA: projetando para brincar.
}

\author{
Michelle Cotrim \\ UEMG \\ michellecotrim@hotmail.com \\ Profa. Dra. Rita A. C. Ribeiro \\ UEMG \\ rribeiroed@gmail.com
}

\begin{abstract}
Resumo: Nota-se que o design de brinquedos contemporâneo está intimamente ligado ao conceito moderno de infância, bem como à percepção que temos quanto as crianças. Sabe-se que esta relação vem sendo construída ao decorrer do tempo e é fruto de uma intricada conjunção de fatores, sociais, econômicos, tecnológicos e culturais. O presente artigo propõe um panorama da interconexão entre estes elementos ao longo do século XX, através da seleção de alguns brinquedos, tendo como base para esta o conceito de blockbuster toy; bem como levando em consideração os movimentos modernos de Design, o contexto histórico no qual este brinquedos foram desenvolvidos, e as interferências à percepção da infância.
\end{abstract}

Palavras-chave: Infância, Design de Brinquedos, Cultura.

\begin{abstract}
Note that the contemporary toy design is closely related to the modern concept of childhood as well as the perception that we have of children. It is known that this relationship has been built up over time and is the result of an intricate combination of social, economic, technological and cultural factors. This article provides an overview of the interrelationship between these elements throughout the twentieth century, by selecting some toys, based on the concept of blockbuster toy; and taking into account the movements of modern design, the historical context in which the toys were developed, and interference to the perception of childhood.
\end{abstract}

Keywords: Childhood, Toy Design, Culture.

\section{INTRODUÇÃO}

O design de brinquedos como é compreendido hoje está intimamente ligado ao conceito moderno de infância, bem como à percepção contemporânea que temos 
quanto as crianças; sabe-se que esta relação vem sendo construída ao decorrer do tempo e é fruto de uma intricada conjunção de fatores, sociais, econômicos e culturais. Ariés (1981) argumenta que a partir do século XVI, é percebida uma mudança na abordagem dada ao termo infância e consequentemente às crianças, que passam a ser compreendidas como seres diferentes dos adultos, o que impulsiona 0 surgimento de criações específicas para este estrato da sociedade, com o intuito de diferenciá-lo do universo adulto. O presente trabalho traça um panorama histórico e social desse processo.

Uma das primeiras mudanças que podem ser verificadas está na alteração dos trajes destinados as crianças (ARIÉS, 1981). A adoção de uma vestimenta específica para a infância no fim do século XVI e sua difusão no século XVII possibilitou o fomento de um novo discurso sobre a infância que a separava da vida adulta, notamos que o infantil tornou-se fortemente conectado a artefatos, que passaram a condensar seu significado. No século XVIII esta relação, entre o que é próprio da criança e o que é próprio do adulto, alcança sua vertente moderna, na qual a criança passa a ser considerada um ser particular porém dependente, que necessita de instrução e meios apropriados para se tornar um adulto funcional. Tais conceitos têm suas raízes no pensamento iluminista Rousseau (1979), defensor que a infância era parte do desenvolvimento natural, e em sua obra Emile: Or On Education, discorre sobre a importância do desenvolvimento das crianças e de como este tem sua origem na natureza; portanto a criança não era considerada um ser completo, afinal era preciso desenvolvê-la, na verdade percebe-se atrelada ao infantil um sentimento de potencialidade, como um porvir.

Para alcançar o status de indivíduo (adulto) a criança deveria adquirir as habilidades típicas de um adulto, Cross (2001) pontua que para um desenvolvimento satisfatório era necessário um ambiente seguro, ferramentas específicas e atividades que promovessem o mesmo, este cenário possibilitou que os brinquedos alcançassem um lugar definitivo e por vezes exclusivo entre as crianças, até então muito mais como uma ferramenta didática do que como instrumento de entretenimento.

A exclusividade dos brinquedos infantis pode ser considerada de certa forma uma novidade do século XVIII, visto que como abordado por Ariés, "no início do século XVII não existia uma separação tão rigorosa [...] entre as brincadeiras e os jogos reservados à infância e as brincadeiras e jogos dos adultos. Os mesmos jogos eram comuns a ambos." (ARIÉS,1981, p.47). Dentre os brinquedos comercializados durante este período pode-se destacar os brinquedos alemães, devido a sua importância na formatação de uma indústria de brinquedos ( CROSS, 2001; FLEMING, 2001) .

Os brinquedos alemães eram peças em madeira, em sua maioria réplicas/miniaturas de objetos/cenários da vida cotidiana destinados inicialmente ao universo adulto. Porém com a difusão dos novos ideais iluministas à respeito ao infantil e a função atribuída aos brinquedos, que naquele momento deveriam ensinar valores racionalistas, Cross pontua que no fim do século XVIII as mesmas casas de bonecas passam a ser projetadas especialmente para garotas, com o intuito de educálas para o cuidado da casa. Percebemos que a relação dos brinquedos com a infância favorece a produção de brinquedos que refletissem os valores desejáveis do universo adulto, levando em consideração os avanços tecnológicos, bem como ferramentas que promovessem o aprendizado. 
Com a chegada do século XIX o processo de utilizar brinquedos como elementos didáticos se consagra, definindo de certa forma a infância como uma etapa a ser concluída através do desenvolvimento gradual. Ao tratar do brinquedo moderno, Cross os descreve como um novo e diferenciado produto fruto de uma nova visão de negócio e educação de filhos, "tanto produtores quanto pais enviavam para a juventude a mensagem que brincar era seu trabalho e os brinquedos suas ferramentas." (CROSS, 2001, p.12, tradução nossa)

Este fenômeno pode ser ilustrado através dos trabalhos desenvolvidos por Friedrich Fröebel, pedagogo alemão que idealizou e implantou o primeiro jardim de infância adotando a filosofia na qual o aprender se dava através do brincar. Para Fröebel, a brincadeira faz parte da natureza humana e é responsável por nos instigar a descobrir o funcionamento das coisas através da exploração do que nos rodeia. Como forma de implementação desta filosofia ao design de brinquedos, Fröebel desenvolveu a série Gifts em 1837.

\section{Século XX: um novo olhar sobre a infância.}

O século XX foi atravessado por diversos fatos que mudaram o curso da história, começamos andando a cavalo e terminamos com trens balas, atravessamos duas guerras mundiais e resistimos à Guerra Fria, vimos o homem alcançar o espaço e assistimos o naufrágio da ideia de progresso, presenciamos o nascer de movimentos e a morte da ideologia; foram cem anos que aceleraram e relativizaram o tempo (EINSTEIN, 1915), que dividiram e planificaram o mundo (FRIEDMAN, 2005), que presenciaram a vida de sólida se tornar líquida (BAUMAN, 2001), que vivenciaram o amadurecimento, a ampliação e a complexidade do design (FIELL; FIELL, 2005); cem anos nos quais a infância de etapa apenas biológica passou a ser analisada por um escopo psicanalítico e as crianças de meros espectadores passaram a ocupar o espaço de atores sociais.

Diante deste cenário, considerando que os brinquedos são produtos de design e apoiados na fala de Charlotte e Peter Fiell (2005), segundo os quais "os produtos de design não podem ser totalmente compreendidos fora dos contextos social, econômico, político, cultural e tecnológico que levaram a sua concepção e realização" (FIELL; FIELL, 2005, p.07); apoiados em Brown (1996), autor que sugere que os brinquedos são uma espécie de espelho da sociedade, e baseados nas proposições de que a pluralidade do design moderno reside também nas "alterações de padrões de consumo, de gosto, alterações de imperativos comerciais e morais de inventores, designers, fabricantes, progresso tecnológico e variações de tendências" (FIELL; FIELL, 2005, p.07), foram selecionados alguns brinquedos com o propósito de discutir a relação infância, design e brinquedos nos séculos $X X$, adotando como pontos de apoio para a seleção destes: a relevância em relação aos movimentos de Design, o conceito de blockbuster toy e as interferências diretas à percepção da infância.

Quanto aos movimentos de Design "podemos perceber que, desde a virada do século, o design desenvolveu-se através da sucessão de oficinas experimentais que ficaram conhecidas como escolas [...] " (BRANZI, 2013, p.130), de acordo com Branzi (2013) cada uma delas propunha uma visão particular do ser humano e da humanidade inserida na construção da Modernidade. 
O conceito de blockbuster toy ou brinquedo de sucesso foi elaborado por Vecchio (2003), e segundo o autor podemos dividir o blockbuster toy em dois tipos: os persistentes e os de novidade. Os persistentes são aqueles que passam de geração para geração, muitas vezes introduzidos pelos pais aos filhos, como exemplo podemos citar a boneca Barbie e o Teddy Bear; os brinquedos de novidade "tendem a estourar na cena cultural pop, por vezes baseados no lançamento de um novo filme. [...] Incluem também brinquedos que ganharam notoriedade devido a sua nova perspectiva" (VECCHIO, 2003, p.26), como exemplo o autor cita a primeira geração do Furby (1998), que apesar de elementos comuns ao exemplo anterior apresentam uma estética diferenciada e o uso de sistemas eletromecânicos.

Dentre os dois tipos o autor aponta que geralmente o primeiro tipo sobressai ao segundo; Byrne (2013) completa este apontamento ao colocar que "brinquedos clássicos compartilham um tecido cultural que transcende tudo: raça, classe, gênero e até mesmo o tempo" (BYRNE, 2013), sendo assim podemos entender que no século XX o brinquedo de sucesso persistente ou o brinquedo clássico está intimamente conectado a cultura vigente; e pelo fato de geralmente serem uma espécie de legado (passado de pais para filhos) revitalizado, visto que apesar de os nomes permanecerem os mesmos a cada versão são agregadas características próprias de um período de tempo específico. Percebemos uma carga de fator afetivo/emocional não somente aos brinquedos, mas também ao período da infância.

\title{
2.1. 1900- 1920: brincando com as emoções
}

Nas primeiras décadas do século $X X$, no campo tecnológico os avanços industriais levaram a uma crença no progresso, e no campo pedagógico os Gifts de Fröebel se popularizaram contribuindo para a transformação no modo como a infância era percebida pela sociedade; segundo a exposição Growing by Design :

\begin{abstract}
Para muitos designers, escritores, e reformistas na virada do século $\mathrm{XX}$, as crianças eram o símbolo vivo das mudanças radicais que conduziram ao surgimento da Modernidade. Enquanto focavam nos medos do milênio e sonhos utópicos, elas [crianças] pareciam um fonte inesgotável de renovação, evocando um paraíso perdido no passado remoto e a possibilidade futura de uma cidade ou estado ideal. (CENTURY.., 2012, tradução nossa)
\end{abstract}

Estas transformações passam a impregnar o desenvolvimento de brinquedos, o que pode ser percebido nos blockbuster toys desta década, segundo Vecchio: Lionel Trains, Crayola Crayons e Teddy Bear. Sendo assim verificamos uma certa continuidade a linha de pensamento até então vigente (os brinquedos de maior sucesso representavam os avanços tecnológicos e os interesses de aprendizado/ensino), porém podemos perceber uma mudança com a entrada do Teddy Bear.

O Teddy Bear chegou ao mercado em 1903 e pode ser apontado como eco cultural da estória Cachinhos de Ouro e os Três Ursos ${ }^{1}$, de 1834. Um dos pontos relevantes à respeito dos teddies é que estes fogem dos padrões até então estabelecidos para o desenvolvimento de brinquedos. Até este ponto os brinquedos tinham uma função objetiva, preparar para a vida adulta; as meninas deveriam aprender através dos brinquedos (bonecas bebês, louças em miniatura, casas de

\footnotetext{
${ }^{1}$ História infantil registrada primeiramente pelo autor e poeta inglês Robert Southey.
} 
bonecas) as funções esperadas para uma mulher adulta e os meninos deveriam adquirir os conhecimentos necessários para, ao se tornarem homens, serem hábeis para escolher uma ocupação (arquiteto, engenheiro, entre outros), mas a partir da introdução dos teddies, os brinquedos passam também a promover a criação de laços afetivos das crianças com os mesmos, sendo assim percebemos o acréscimo de um novo valor na concepção e na comercialização dos brinquedos, o emocional. Kline (1995) corrobora com este apontamento ao afirmar que "as crianças respondem a fofura do teddy com um profundo apego, o qual elas deram aos poucos a outros objetos. Isto fez com que os fabricantes de brinquedos percebessem que a relação das crianças com os bens são guiadas por escolhas emocionais e não racionais." (KLINE,1995, p.150, tradução nossa)

Dada a ligação profunda entre a infância e os brinquedos, verificamos que ao adicionar o aspecto afetivo aos mesmos, isto demonstra uma modificação na percepção da infância, que agora envolta em uma aura de inocência, passa a ser considerada uma fase especial, um período a ser preservado; a adição do elemento emocional ao universo dos brinquedos permitiu também um maior envolvimento da criança com os mesmos modificando a relação até então existente.

A partir de 1914 verifica-se que o mundo experimentou uma guerra ( Primeira Guerra Mundial) de proporções globais, que assolou principalmente o continente europeu, porém em meio a destruição houveram avanços tecnológicos e industriais, bem como o reforço de um sentimento nacionalista embrionário que viria a instigar a ascensão do governo nazista na Alemanha e do governo fascista na Itália e a dar corpo em 1917 a revolução Russa.

No mesmo período surgiam os movimentos do Construtivismo e De Stjil que influenciaram e moldaram de certa forma o design moderno. O Construtivismo nasceu na Rússia como resposta a busca de "um esquema mais democrático de produção e distribuição de bens" (FIELL; FIELL, 2005, p.176) O De Stjil surgiu na Holanda na forma de um jornal de arte que discutia arte e design, desde as novidades do avant-garde holandês, bem como o construtivismo russo, o discurso dadaísta e o futurismo italiano, empregavam formas geométricas simples e blocos de cores; O De Stjil não se opunha aos movimentos anteriores apenas por discordâncias estéticas, mas por acreditar que cada tempo necessita de uma expressão própria, nas palavras de Gerrit Rietveld, um de seus membros mais efetivos: "nós não evitamos os estilos anteriores porque estes são feios, ou porque não podemos reproduzi-los, mas porque nosso tempo demanda sua forma própria , quero dizer sua própria manifestação" (OVERY,1988, p.73), este movimento abarcou diversos segmentos do design, incluindo o design de brinquedos (figura 1). 


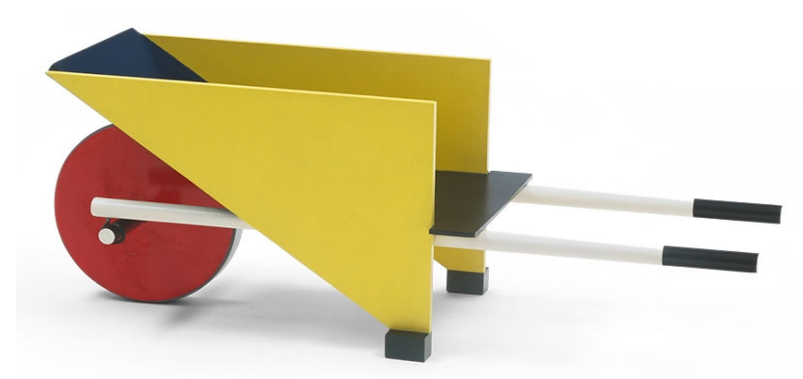

Figura 1: "Carrinho de mão Rietveld" Fonte: CENTURY...,2012

Em 1919 foi fundada em Weimar por Walter Gropius a Escola Bauhaus (FIELL; FIELL, 2005), que integrava a teoria e a prática do design através dos novos meios de produção que ficaram disponíveis com o fim da guerra (1918). A Escola surgiu embasada em uma vertente social, simbólica e intelectual, na qual os alunos após o primeiro ano se organizavam em oficinas sob a direção dos "mestres" (professores); em 1925 a Bauhaus se muda para Dessau, uma cidade industrial, inferindo desta maneira mudanças na estrutura da Escola, que se aproxima do design industrial e por consequência adota uma visão mais funcionalista, a Escola encerra suas atividades na Alemanha em 1933.

Como consequência da Primeira Guerra, em relação ao design de brinquedos, além da disponibilidade de novos materiais e técnicas industriais, o fim da guerra possibilitou que alguns arquitetos enveredassem pelo design de brinquedos, visto que ocasionou, de certa maneira, uma pausa na construção civil. Dentre estes estava o arquiteto expressionista alemão Bruno Taut, que desenvolveu no ano de 1919, em Berlim, o brinquedo de construção Dandanah (Palácio das Fadas), um conjunto de montar de 62 peças em vidro colorido.

\subsection{0 - 1940: construindo o futuro}

Com a criação da Bauhaus o cenário do fazer e ensinar design se modifica, dentre as metodologias de ensino adotadas pela a Escola, podemos destacar o método desenvolvido por Fröebel; percebemos que sua utilização inspirou algumas das incursões ao design de brinquedo por parte dos membros da Bauhaus, que desenvolveram brinquedos que procuravam estimular a criatividade, e ressalta-se que estes passaram a representar um fonte de receita para a Escola (CENTURY... , 2012). A partir destes relatos pode-se inferir que existia uma preocupação específica com o desenvolvimento criativo das crianças, reflexo da nova posição que a infância assume perante a sociedade.

Verificamos que os Gifts além de influenciar o design da Bauhaus representaram uma fonte de inspiração para diversos brinquedos deste período, dentre os quais destacamos os blocos de montar, visto que eram uma temática recorrente. Como exemplo podemos citar entre outros os de autoria de Josef Franz Maria Hoffmann em 1920, de Lyonel Feininger produzidos de 1925 à 1955, de Joaquín Torres-Garcia em 1928, de Ladislav Sutnar em 1940. 
Um blockbuster toy introduzido neste período (1920-1940) foi o jogo de tabuleiro Monopoly em 1934, criado pelo engenheiro Charles Darrow e comercializado por Parkers Brothers Inc. nos Estados Unidos que ainda se recuperava do Crash da bolsa em 1929 e da Grande Depressão. O Monopoly, que mais tarde ganhou uma versão brasileira (licenciada a Estrela sob o nome de Banco Imobiliário), talvez em reflexo a pobreza em massa e em oposição a maioria de seus antecessores que atribuíam a vitória a virtude, trazia como objetivo central o acúmulo e bens e riquezas e o ganhar às custas da derrocada alheia. Nota-se que os jogos de tabuleiro através do seu objetivo central carregam um discurso a partir do qual poder ser vinculado um determinado comportamento, pode-se citar o uso dos jogos de tabuleiro e outros brinquedos pelo governo nazista e fascista, que apregoavam os princípios ideológicos e encorajavam o engajamento às forças militares .

Também durante a década de 30 se popularizou nos Estados Unidos o Streamlining, que como o nome diz evocava a aerodinâmica, sendo assim o dinamismo, o movimento e apesar de ter surgido no design de meios de transporte logo foi adaptado para outros setores do design. Uma das características marcantes deste estilo são o formato de gota alongada e o uso de linhas horizontais para reforçar a ideia de velocidade. $O$ design de brinquedos também adotou este estilo como podemos observar no patinete Skippy-Racer (figura 2) de Jonh Rideout e Harold Van Doren.

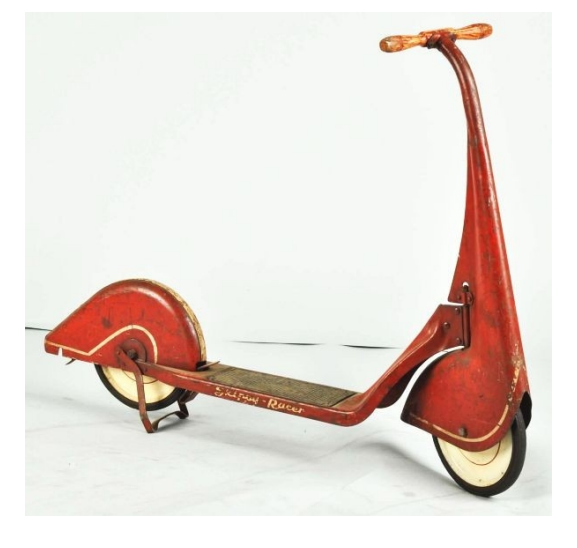

Figura 2: "Skippy Racer" Fonte: CENTURY...,2012

\subsection{0-1960: criando fantasias}

Em 1939 tem inicio a Segunda Guerra Mundial, após seis anos de destruição em massa a guerra termina com a declaração de vitória dos Aliados; os avanços tecnológicos da Segunda Guerra possibilitaram o desenvolvimento de novos materiais que aos poucos modificaram o design de produto.

Em 1947, retomando a temática no design de brinquedos pré Segunda Guerra, dos blocos de montar, Ole Christiansen, um desenvolvedor e fabricante dinamarquês de brinquedos em madeira, percebe o potencial inovador do uso do plástico ABS (recém desenvolvido) para o design de brinquedos e em conjunto com uma indústria inglesa desenvolve a primeira geração do sistema de tijolos de plástico ocos que são nomeados de Lego System . Dez anos após o seu lançamento, Godtfred, filho de Ole, começa a redesenhar os tijolos; após a produção de vários protótipos, os novos modelos foram submetidos a teste por crianças em Copenhague, que optaram pelo 
stud-tube coupling, lançado no mercado no ano seguinte. Com base dos dados acima copilados, verificamos que a postura diante da criança mudou significativamente, em relação ao inicio do século, pois de espectadores passivos que recebem os brinquedos prontos, as crianças passam a ter voz, no caso do design de brinquedos, sua opinião modifica e interfere no processo.

O design da década de 50 retomou os conceitos racionalistas difundidos pela Bauhaus nos anos 30 através do Good Design ${ }^{2}$, nota-se também a partir deste momento, um interesse sobre a criatividade das crianças, não mais com o propósito de desenvolvê-la e sim no intuito de se aprender com ela, como pode-se verificar no trabalho do designer italiano Bruno Munari; e também a inserção mais freqüente da figura da criança nos projetos de design, segundo Branzi "a maioria dos designers italianos da década de 1950 e 1960 fizeram referência, pelo menos visualmente, à presença das crianças, vistas como interlocutores ideais para seus projetos e produtos"(Branzi, 2013, p.131).

Sendo assim, pode-se indicar a partir dos anos 50 há um maior interesse do design na figura da criança, o que proporcionou um aumento na diversidade, produção e comercialização de brinquedos. Outra abordagem que pode ser dada a esta expansão pode ser explicada a partir da fala de Byrne: "como a cultura passou de agrária para industrial para baseada na informação, as crianças do período pós-guerra tinham o luxo de serem crianças por mais tempo adiando as responsabilidades de ser adultos" (BYRNE,2013,p.12, tradução nossa). Portanto, verifica-se que a um aumento ao tempo dedicado a infância, despertando assim uma maneira diferenciada de enxergar a criança. Outro ponto é que o fim da Segunda Guerra promoveu diversas mudanças na sociedade, Kline (1995) pontua que os fabricantes de brinquedos ao perceberem as modificações em relação a percepção da infância, vista sob um viés sociológico, e as alterações na condição familiar desenvolveram uma nova estratégia de negócio.

Pode-se apontar como sinalizador deste fenômeno a popularização no uso da televisão como veículo para a publicidade voltada para as crianças, sendo que neste período, a TV se tornou uma das formas mais eficientes de comunicação entre as indústrias de brinquedos e as crianças por meio da vinculação de comerciais. A prática de anúncios voltados para o público infantil não era uma novidade, nas décadas de 30 e 40 era comum a utilização do rádio como meio de publicidade para produtos voltados para público infantil, porém o advento da TV modificou a forma como os brinquedos eram apresentados, a utilização da figura da criança, permitia uma melhor visualização do potencial da brincadeira e uma maior identificação com os brinquedos por parte das crianças. O primeiro comercial de brinquedos anunciava o lançamento do Mr. Potato Head em 1951 (Cross,2001).

Em 1955 o surgimento do Mickey Mouse Club House, um programa televisivo de variedades voltado para o público infantil modificou a indústria de brinquedos, Cross pontua que o programa possibilitou a criação de uma nova forma de se comercializar brinquedos, vendendo-os diretamente para as crianças (CROSS, 2001, p.165), visto que abriu espaço para a publicidade televisiva voltada para este público. $\mathrm{O}$ autor indica também que um dos pioneiros em utilizar este novo canal foi a Mattel; seu primeiro comercial vinculado no Mickey Mouse Club House mostrava um garoto

${ }^{2} \mathrm{Na}$ Alemanha o Good Design refletiu na fundação da Escola de Ulm em 1952. 
com uma espécie de metralhadora na sala de sua casa que imaginava estar em uma savana africana caçando elefantes. Verifica-se que o foco deixa de ser o produto e passa a ser a relação entre a criança e o brinquedo, a possibilidade da brincadeira, o faz-de-conta (CROSS, 2001).

A abertura deste novo canal de comunicação entre crianças e fabricantes de brinquedos de certa forma heterogeneizou a infância, "brincar se tornou o modelo visível da unificação da cultura de massa infantil - juntando as áreas de uso e as posses comuns do cotidiano" (KLINE,1995, p.148, tradução nossa), Kline prossegue descrevendo que esta universalização da infância, através da publicidade e da produção em massa de brinquedos, refletiu no processo de socialização da criança (entendido aqui como a percepção da criança como ator social); promovendo a formatação do mercado consumidor infantil.

Em 1959 é introduzida no mercado, através também de um comercial durante - Mickey Mouse Club House uma das bonecas mais vendidas de todos os tempos sendo assim constituída como um blockbuster toy, a boneca Barbie; inspirada na boneca alemã Bild Lilli (figura 3), que por sua vez foi criada a partir de uma personagem de tirinha do jornal Bild-Zeitung.

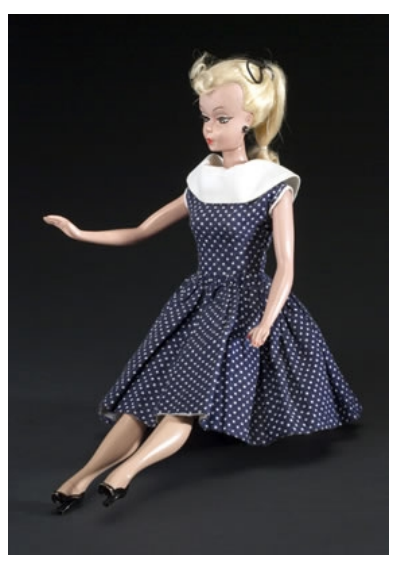

Figura 3: "Boneca Bildi Lilli" Fonte: FASHIONDOLLS...,2013

Desde de sua criação a boneca Barbie influenciou e continua influenciando a cultura e o design de brinquedos, sendo que um dos diferenciais na sua constituição é que em oposição as bonecas comuns a sua época, esta se apresentava como um indivíduo adulto/jovem, e desenhada não apenas como uma nova boneca, mas como uma personalidade (KLINE, 1995). O sucesso da Barbie inspirou diversas versões semelhantes ao redor do mundo como por exemplo a boneca Suzi da fabricante Estrela.

\subsection{0 - 1980 : consumindo narrativas}

Desde o encerramento da Segunda Guerra, o mundo passou por diversas ocorrências que transformaram a sociedade: guerras que despertaram movimentos de paz e inspiraram a celebração da liberdade; revoluções que polarizaram o mundo (Guerra Fria), ocasionaram mudanças de regimes políticos e embargos econômicos e a corrida para alcançar o espaço. 
No design a celebração da cultura pop (cultura popular de consumo americana) emergente na década de 50 começou a surtir efeito nos anos 60 , por meio do Pop Design que "começou a manifestar-se nos objetos de uso diário, pois os designers enveredaram por uma aproximação menos série e mais jovem do que a que era oferecida pelo Good Design dos anos 50." (FIELL; FIELL, 2005, p.565) O Pop Design findou com os últimos reflexos da austeridade dos tempos de guerra através de um otimismo refletido no uso de cores brilhantes e formas arrojadas, e muitos dos produtos desenvolvidos neste período utilizaram o plástico como material principal. Alguns destes aspectos do Pop Design podem ser percebidos também no design de brinquedos, como exemplo da adoção da estética pop nos brinquedos pode-se citar o Playmobil.

Inicialmente foram produzidos três bonecos: um cavaleiro, um operário e um índio americano, percebemos elementos de narrativa através da escolha da criação de bonecos temáticos/personagens que exaltam ao mesmo tempo a fantasia (cavaleiro) e a aventura (índio americano) bem como o cotidiano (operário).

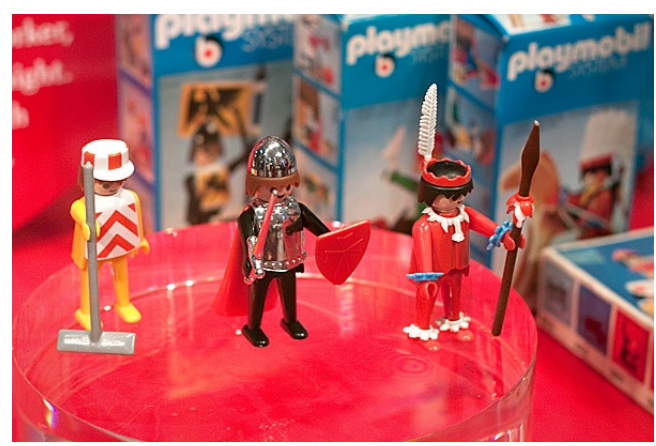

Figura 4: "Playmobil"

Fonte: CNBC...,2013

Percebe-se que a fantasia e a aventura são elementos que podem ser identificados também em alguns blockbusters toys das décadas setenta e oitenta como, por exemplo, os action figures de Star Wars (1978), He-Man (1983), Tartarugas Ninjas (1987) e Transformers (1984) entre outros. Verifica-se também a crescente associação dos brinquedos à séries televisivas e à produções cinematográficas, o que de acordo com Susan Thomas (2007) devido a utilização da televisão como babysitter e a relação cada vez mais próxima entre a cultura de consumo, os brinquedos e a televisão, provocou pela primeira vez um afastamento (estranhamento) dos pais das brincadeiras dos filhos.

Outro ponto a ser ressaltado na infância nos anos setenta e oitenta foi a utilização da tecnologia como entretenimento, por vezes conectados à brinquedos já conhecidos como no caso do Teddy Ruxpin (uma espécie de versão falante do Teddy Bear) e no desenvolvimento de novos produtos como o Atari, Intellvision Video Game System, Nintendo e Game Boy.

\section{Geração Y: Growing by Design}

No fim do século XX verifica-se que diferentes campos acadêmicos passam a redefinir o discurso sobre a criança, Rushkoff (1996), pontua que a interação das crianças com as telas criou uma nova forma de vivenciar a infância provocando uma 
modificação na maneira de compreender o mundo; essa "criança das telas" se adapta rapidamente aos cenários em constante mudança e se aproxima do universo adulto dissolvendo os limites antes bem estabelecidos entre o que é próprio do infantil e o que é próprio do adulto.

No contexto do design verifica-se que surgem novas altercações à respeito da relação design/infância e em 1990 aconteceu em Aspen a quadragésima Conferência Internacional de Design sob o título Growing by Design. Foi a primeira vez que a Conferência dedicou-se a discutir a relação entre a criança e o design; segundo os realizadores o conceito era: um olhar recíproco entre designers, crianças e design. A conferência contou com a presença de profissionais de variadas áreas, e crianças que participaram de fóruns e oficinas, durante a conferência foram abordados temas como a influência da cultura adulta no comportamento infantil, o papel do design na formação das crianças, entre outros.

O cenário do design de brinquedos se expande e, aos poucos, se desmaterializa, passa a se ocupar não apenas no desenvolvimento de artefatos físicos mas também na criação de universos quiméricos para serem usufruídos através das telas de computadores e televisores. Isto popularizou o gênero dos jogos eletrônicos, o que pode ser notado através dos blockbuster toys deste período (VECCHIO, 2003) dentre os quais estão o jogo para computador Myst (1993), cuja a trama se desenvolve em um mundo fantástico e apresenta múltiplas possibilidades de finais; o jogo para vídeo game Tomb Raider (1996), no qual a personagem principal, Lara Croft (figura 5), é uma arqueóloga inglesa ao estilo Indiana Jones; e o jogo on-line EverQuest (1999), que popularizou o gênero de RPG online multiplayer massivo.

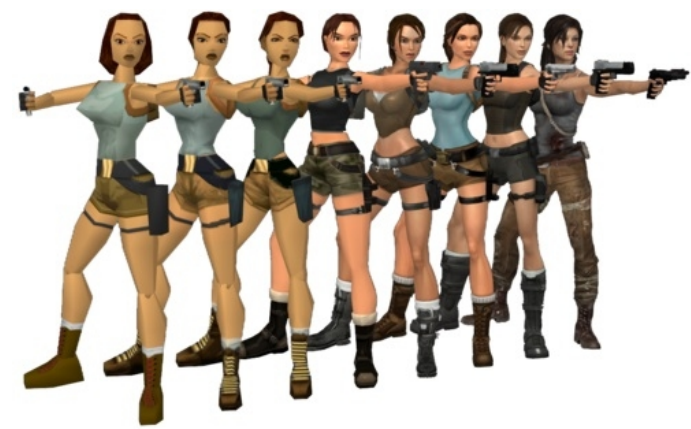

Figura 5: "Lara Croft: 1996 - 2013 " Fonte: GAME...,2014

Nota-se também um deslocamento da "cultura pop" infantil de norteamericana para japonesa, uma espécie de japonificação (PHOENIX, 2006; ALLISSON, 2006), permeada por animes, filmes, livros, mangás e brinquedos, dentre os quais pode-se destacar o jogo portátil Tamagotchi (1996) e o jogo para GameBoy Pokemón (1998) (VECCHIO, 2003).

\section{CONSIDERAÇÕES FINAIS}

A partir da investigação da relação entre o design e infância no século $X X$, percebe-se que, no decorrer desse período, as modificações inerentes ao conceito de infância, bem como as modificações socioculturais relativas ao tema foram incorporadas ao design de brinquedos. 
Verificamos ainda que a partir de 1900 os brinquedos passaram a estimular uma nova forma de conexão com os usuários, mais profunda e visceral. Contagiado pelo sentimento de progresso e reconstrução, o design de brinquedos se propôs a construir o futuro com um bloco de cada vez. E, ao perceber o potencial das novas mídias, se apropriou das telas e inverteu o jogo, passando a criar fantasias que evoluíram em narrativas e estimularam o consumo.

No fim do século XX nota-se que o design de brinquedos se miniaturalizou em cartuchos e se desmaterializou através de downloads, migrou do sonho americano para a terra do sol nascente e em meio a estas mudanças, unificou e formatou o comportamento de crianças ao redor do mundo.

\section{REFERÊNCIAS}

ALLISON, A. Millennial Monsters: Japanese Toys and the Global Imagination. Berkeley: University of California: 2006.

ARIÉS, P. História Social da Criança e da Família. (trad. Dora Flaksman) 2a ed. Rio de Janeiro: Guanabara, 1986.

BAUMAN, Z. Modernidade Líquida. Rio de Janeiro: J.Zahar, 2001.

BRANZI, A. Educação e Espaço Relacional. In: CEPPI, G. ; ZINI,M. et al. (Org.) Crianças, Espaços, Relações: Como Projetar Ambientes para a Educação Infantil. Trad. Patricia Helena Freitag. São Paulo: Penso, 2013.

BROWN,K. The British Toy Business: A History Since 1700. Londres:Hambledon, 1996.

BYRNE,C. Toy Time!: From Hula Hoops to He-Man to Hungry Hungry Hippos: A Look Back at the Most- Beloved Toys of Decades Past. New York: Three Rivers Press, 2013.

CENTURY..., Century of the child: Growing by Design. Disponível em: <http://www.moma.org/interactives/exhibitions/2012/centuryofthechild> Acesso em: 21 dez. 2013.

CROSS, G. Kids' Stuff: Toys and the Changing World of American Childhood. Cambridge: Harvard, 2001.

FIELL,C., FIELL,P. Design do Século XX. Tradução João Bernardo Boléo. Köln:Tashen, 2005.

FLEMING,D. Powerplay: Toy as Popular Culture. New York: Manchester, 1996.

FRIEDMAN,T. O Mundo é Plano: uma Breve História do Século XXI. Tradução de Cristiana Serra S. Duarte. Rio de Janeiro: Objetiva, 2005.

FROEBEL. Brief History of the Kindergarten. Disponível em: <http://www.froebelgifts. com/history.htm> Acesso em: 20 dez. 2013.

KLINE,S. Out of the Garden: Toys and Children's Culture in the Age of TV Marketing. London: Verso, 1995. 
PHOENIX,W. Plastic Culture: How Japanese Toys Conquered the World. Tokyo: Kodansha, 2006.

PROUT, A. The future of childhood. New York: Routledge Falmer, 2005.

ROUSSEAU, J. , 1979. Emile: or On Education. Tradução Allan Bloom.

RUSHKOFF, D. The Children of Chaos. Disponível em: <http://www.rushkoff.com/playi ng-the-future/>Acesso: 15 dez. 2013)

SIROTA, David. Back to Our Future: How the 1980s Explain the World We Live in Now - Our Culture, Our Politics, Our Everything. New York: Ballantine, 2011.

THOMAS,Susan . Buy,Buy Baby: How Consumerism Manipulates Parents and Harms Young Minds. New York: Houghton Mifflin Company, 2007

VECCHIO,G. The Blockbuster Toy! How to Invent the Next Big Thing. Louisiana: Pelican, 2003. 